\title{
NEW FAUNISTIC AND TAXONOMIC DATA ON ORIBATID MITES (ACARI, ORIBATIDA) OF PERU
}

\author{
Sergey G. Ermilov ${ }^{*}$ and Stefan Friedrich ${ }^{2}$
}

\author{
${ }^{1}$ Tyumen State University, Tyumen, Russia \\ ${ }^{2}$ Zoologische Staatssammlung München, München, Germany \\ "corresponding author; e-mail: ermilovacari@yandex.ru
}

\begin{abstract}
The present study is based on oribatid mite material (Acari, Oribatida) collected during an expedition to Amazonian Peru in May 2015. A list of identified taxa, including 56 species from 36 genera and 23 families, is presented; of these, eight species (Neoamerioppia phoretica, Ceratorchestes globosus, Truncozetes ecuadoriensis, Drymobates silvicola, Dynatozetes amplus, Scheloribates elegans, Allogalumna antillensis, Galumnopsis secunda), five genera (Drymobates, Dynatozetes, Allogalumna, Sacculogalumna, Galumnopsis) and two families (Drymobatidae, Galumnellidae) are recorded in Peru for the first time, the genus Sacculogalumna is recorded in the Neotropical region for the first time. A new species of Sacculogalumna (Galumnidae) is described; S. hexasacculata Ermilov sp. $\mathrm{n}$. is similar to S. samarensis Ermilov et Corpuz-Raros, 2017, but differs by the presence of striate pattern on dorsal and ventral sides of body, rounded rostrum, smooth bothridial setae, complete sejugal suture, short and thin anal and adanal setae, setiform genital and central epimeral setae and two setae on anterior edges of genital plates, and the paraanal position of adanal lyrifissures in females and males.
\end{abstract}

KEY WORDS: Mites, Amazonian Peru, fauna, list of taxa, record, new species, systematics, Sacculogalumna.

DOI: 10.21684/0132-8077-2017-25-1-3-13

\section{INTRODUCTION}

Presently, the Peruvian oribatid mites (Acari, Oribatida) are actively investigated (e.g. Ermilov and Gwiazdowicz 2015; Ermilov 2016; Ermilov and Friedrich 2016; Ermilov et al. 2016). This work is final part of our faunistic and taxonomic study (Ermilov and Friedrich 2017) of oribatids collected during a one-month expedition to Amazonian Peru organized by the Bavarian State Collection of Zoology (Germany) in May 2015. The primary goal of the paper is to present a list of the identified taxa, including data on new records.

The secondary goal of the paper is to describe and illustrate a new species under the name $\mathrm{Sac}$ culogalumna hexasacculata Ermilov sp. n. Sacculogalumna was proposed by Engelbrecht (1973) with Sacculogalumna saccularis Engelbrecht, 1973 from South Africa as type species. Later, Liang et al. (2012) described S. suiyangensis Liang, Yang et Huang, 2012 from southern China, and Ermilov and Corpuz-Raros (2017) described S. samarensis Ermilov et Corpuz-Raros, 2017 from the Philippines. An identification key to all these species of the genus and the discussion on some generic morphological traits (including position of lamellar setae) of Sacculogalumna are given by Ermilov and Corpuz-Raros (2017).

\section{MATERIAL AND METHODS}

Material. The specimens were collected in South America, Amazonian Peru, 09 $37^{\prime} \mathrm{S}$, $74^{\circ} 56^{\prime} \mathrm{W}$, Huánuco Department, Puerto Inca Prov- ince, Yuyapichis District, Área de Conservación Privada, Panguana (biological field station), near Rio Yuyapichis (river), $230 \mathrm{~m}$ a.s.1., upper soil and leaf litter in the primary evergreen lowland rainforest, Winkler extraction, 1.V.2015-21.V.2015 (S. Friedrich and F. Wachtel).

All specimens (except the holotype and some paratypes) are in the collection of the Tyumen State University Museum of Zoology, Tyumen, Russia.

Methods. Specimens were mounted in lactic acid on temporary cavity slides for measurement and illustration. Body length was measured in lateral view, from the tip of the rostrum to the posterior edge of the ventral plate. Notogastral width refers to the maximum width in dorsal aspect. Lengths of body setae were measured in lateral aspect. All body measurements are presented in micrometers. Formulas for leg setation are given in parentheses according to the sequence trochanter-femur-genu-tibia-tarsus (famulus included). Formulas for leg solenidia are given in square brackets according to the sequence genu-tibia-tarsus. Morphological terminology used in this paper follows that of F. Grandjean: see Travé and Vachon (1975) for references, Norton (1977) for leg setal nomenclature, and Norton and Behan-Pelletier (2009) for overview. Drawings were made with a camera lucida using a Leica transmission light microscope "Leica DM 2500". 


\section{A LIST OF IDENTIFIED TAXA*}

The list includes number of specimens of each oribatid mite species and notes new records and overall known geographical distribution ${ }^{* *}$ :

\section{Malaconothridae}

Malaconothrus peruensis Hammer, 1961, 1 ex. Distribution: Neotropical region, India.

\section{Trhypochthoniidae}

Archegozetes longisetosus Aoki, 1965, 7 ex. Distribution: Tropics.

\section{Hermanniellidae}

Hermannobates dillerorum Ermilov, 2016, 1 ex. Distribution: Peru.

\section{Carabodidae}

Carabodes (Klapperiches) excellens Balogh et Mahunka, 1969, 1 ex. Distribution: Neotropical region.

\section{Liacaridae}

Xenillus amicorum Ermilov, 2016, 3 ex. Distribution: Peru.

Xenillus davisorum Balogh, 1986, 2 ex. Distribution: Neotropical region.

Xenillus deformatus Balogh et Mahunka, 1969, 1 ex. Distribution: Peru.

\section{Heterobelbidae}

Heterobelba oxapampensis Beck, 1962, 2 ex. Distribution: Neotropical region.

\section{Oppiidae}

Aeroppia friedrichi Ermilov, 2016, 8 ex. Distribution: Peru.

Brachioppia cuscensis Hammer, 1961, 10 ex. Distribution: Neotropical region, India, Japan.

Gittella variabilis Ermilov, Sandmann, Marian et Maraun, 2013, 2 ex. Distribution: Neotropical region.

Lasiobelba (Antennoppia) parachistyakovi Ermilov, 2016, 43 ex. Distribution: Peru.

Neoamerioppia phoretica (Franklin et Woas, 1992), 3 ex. Distribution: Brazil.

\section{Granuloppiidae}

Hammerella (Varioppia) huanucoensis Ermilov, 2016, 1 ex. Distribution: Peru.

\section{Teratoppiidae}

Teratoppia reducta Balogh et Mahunka, 1969, 3 ex. Distribution: Neotropical region.

\section{Suctobelbidae}

Rhynchoppia puertoincaensis Ermilov, 2017, 1 ex. Distribution: Peru.

\footnotetext{
${ }^{*}$ Except ptyctimous mites.

** See mostly Subías (2004, updated 2017).
}

\section{Rhynchoribatidae}

Rhynchoribates (Rhynchoribates) spathulatus Balogh et Mahunka, 1969, 2 ex. Distribution: Neotropical region.

\section{Peloppiidae}

Ceratorchestes (Ceratorchestes) processus Ermilov, 2016, 5 ex. Distribution: Peru.

Ceratorchestes (Paraceratorchestes) globosus Balogh et Mahunka, 1969, 3 ex. Distribution: Bolivia.

Ceratorchestes (Paraceratorchestes) melzeri Ermilov, 2016, 11 ex. Distribution: Peru.

\section{Microzetidae}

Kalyptrazetes bifurcatus Ermilov, 2017, 21 ex. Distribution: Peru.

Schalleria ramosa Balogh et Mahunka, 1969, 1 ex. Distribution: Neotropical region.

\section{Epactozetidae}

Truncozetes ecuadoriensis Ermilov, Sandmann, Marian et Maraun, 2013, 4 ex. Distribution: Ecuador.

\section{Oribatellidae}

Oribatella serrata Balogh et Mahunka, 1969, 10 ex. Distribution: Neotropical region.

\section{Punctoribatidae}

Lamellobates molecula (Berlese, 1916), 6 ex. Distribution: Tropics.

\section{Drymobatidae}

Drymobates silvicola Grandjean, 1930, 4 ex. Distribution: Antilles.

\section{Mochlozetidae}

Dynatozetes amplus Grandjean, 1960, 8 ex. Distribution: Neotropical region.

Dynatozetes sp., 5 ex. It is a new species, which is described in other paper.

Unguizetes incertus (Balogh et Mahunka, 1969), 3 ex. Distribution: Neotropical region.

\section{Haplozetidae}

Paraxylobates sp., 7 ex. It is a new species, which is described in another paper.

Protoribates curvicarinatus Ermilov y Friedrich, 2016, 1 ex. Distribution: Peru.

Protoribates paracapucinus (Mahunka, 1988), 2 ex. Distribution: Cosmopolitan.

Rostrozetes ovulum (Berlese, 1908), 29 ex. Distribution: Tropics, Subtropics.

\section{Scheloribatidae}

Perscheloribates (Perscheloribates) minusculus Hammer, 1961, 1 ex. Distribution: Neotropical region.

Perscheloribates (Perscheloribates) rostratus Hammer, 1958, 14 ex. Distribution: Neotropical region. 
Perscheloribates (Ecuadoribates) olszanowskii Ermilov y Friedrich, 2016, 1 ex. Distribution: Peru.

Scheloribates (Scheloribates) elegans Hammer, 1958, 3 ex. Distribution: Tropics.

Scheloribates (Scheloribates) praeincisus praeincisus (Berlese, 1910), 1 ex. Distribution: Tropics, Holarctic region.

Scheloribates (Scheloribates) praeincisus acuticlava Pérez-Íñigo y Baggio, 1986, 113 ex. Distribution: Neotropical region.

Scheloribates (Bischeloribates) wachteli Ermilov et Friedrich, 2016, 36 ex. Distribution: Peru.

Scheloribates (Hemileius) sp., 15 ex. It is a new species, which is described in another paper.

Urubambates punctatus Hammer, 1961, 1 ex. Distribution: Peru.

\section{Parakalummidae}

Neoribates (Neoribates) peruensis Ermilov, 2016, 14 ex. Distribution: Neotropical region.

\section{Galumnidae}

Allogalumna (Allogalumna) antillensis (Mahunka, 1998), 1 ex. Distribution: Antilles.

Galumna (Galumna) flabellifera Hammer, 1958, 8 ex. Distribution: Tropics, Subtropics.

Galumna (Galumna) laselvae Balogh, 1997, 10 ex. Distribution: Neotropical region.

Galumna (Galumna) parazeucta Ermilov et Friedrich, 2016, 30 ex. Distribution: Peru.

Galumna (Cosmogalumna) ekaterinae Ermilov et Friedrich, 2016, 35 ex. Distribution: Peru.

Pergalumna (Pergalumna) bifissurata Hammer, 1972, 25 ex. Distribution: Polynesia, Neotropical region.

Pergalumna (Pergalumna) decoratissima PérezÍñigo et Baggio, 1986, 4 ex. Distribution: Neotropical region.

Pergalumna (Pergalumna) krisperi Ermilov et Friedrich, 2016, 22 ex. Distribution: Peru.

Pergalumna (Pergalumna) lenticulata Ermilov et Friedrich, 2016, 11 ex. Distribution: Peru.

Pergalumna (Pergalumna) paraboliviana Ermilov et Gwiazdowicz, 2015, 37 ex. Distribution: Peru.

Pergalumna (Pergalumna) parapassimpunctata Ermilov et Friedrich, 2016, 72 ex. Distribution: Peru.

Sacculogalumna hexasacculata Ermilov sp. n., 9 ex. Distribution: Peru.

\section{Galumnellidae}

Galumnopsis secunda (Sellnick, 1923), 11 ex. Distribution: Neotropical region.

Remarks. The list of identified Peruan oribatid mite taxa included 685 specimens, belonging to 56 species from 36 genera and 23 families. Of these, 24 species are known so far only from Peru, 22 species from the Neotropical region and other 10 species have more wide geographic distribution. The largest number of species belongs to the families Galumnidae (12 species), Scheloribatidae (9) and Oppiidae (5) and the genera Pergalumna (6), Scheloribates (5) and Galumna (4). The largest number of specimens belongs to the species Scheloribates (Scheloribates) praeincisus acuticlava (113 ex.) and Pergalumna (Pergalumna) parapassimpunctata (72 ex.). Eight species (Neoamerioppia phoretica, Ceratorchestes globosus, Truncozetes ecuadoriensis, Drymobates silvicola, Dynatozetes amplus, Scheloribates elegans, Allogalumna antillensis, Galumnopsis secunda), five genera (Drymobates, Dynatozetes, Allogalumna, Sacculogalumna, Galumnopsis) and two families (Drymobatidae, Galumnellidae) are recorded in Peru for the first time. One genus (Sacculogalumna) is recorded in the Neotropical region for the first time.

\section{SYSTEMATICS}

\section{Sacculogalumna hexasacculata Ermilov sp. $\mathbf{n}$.}

Figs. 1-20

Diagnosis. Body size: 1012-1178 × 879-996. Body surface microgranulate, prodorsum, notogaster, pteromorphs, anogenital region, genital and anal plates striate, epimere I and anterior part of pteromorphs reticulate. Rostrum rounded. Prodorsal setae setiform, well-developed, rostral and lamellar setae barbed, interlamellar setae, sparsely barbed, bothridial setae smooth, in longest, ro shortest. Sejugal suture complete. Notogastral lenticulus present. Three pairs of notogastral sacculi, $S a$ located between $l a$ and $l m$. Median pore absent. Subcapitular setae of medium size, $h$ and $m$ barbed, $a$ slightly barbed. Lateral parts of anterior tectum of epimere I with one or two small teeth. Circumpedal carinae long. Epimeral setal formula $2-0-2-3$; $1 c$ represented by alveoli, other setae thin, slightly barbed, $3 c$ and $4 c$ longest. Anogenital setae setiform, genital setae of medium size slightly barbed, aggenital, anal and adanal setae smooth. Adanal lyrifissures located parallel to anal plates. Postanal porose area elongate oval. Leg claws barbed on dorsal sides.

Description. Measurements. Very large species. Body length: 1079 (holotype: male), 1012-1178 (eight paratypes: four females and four males); 


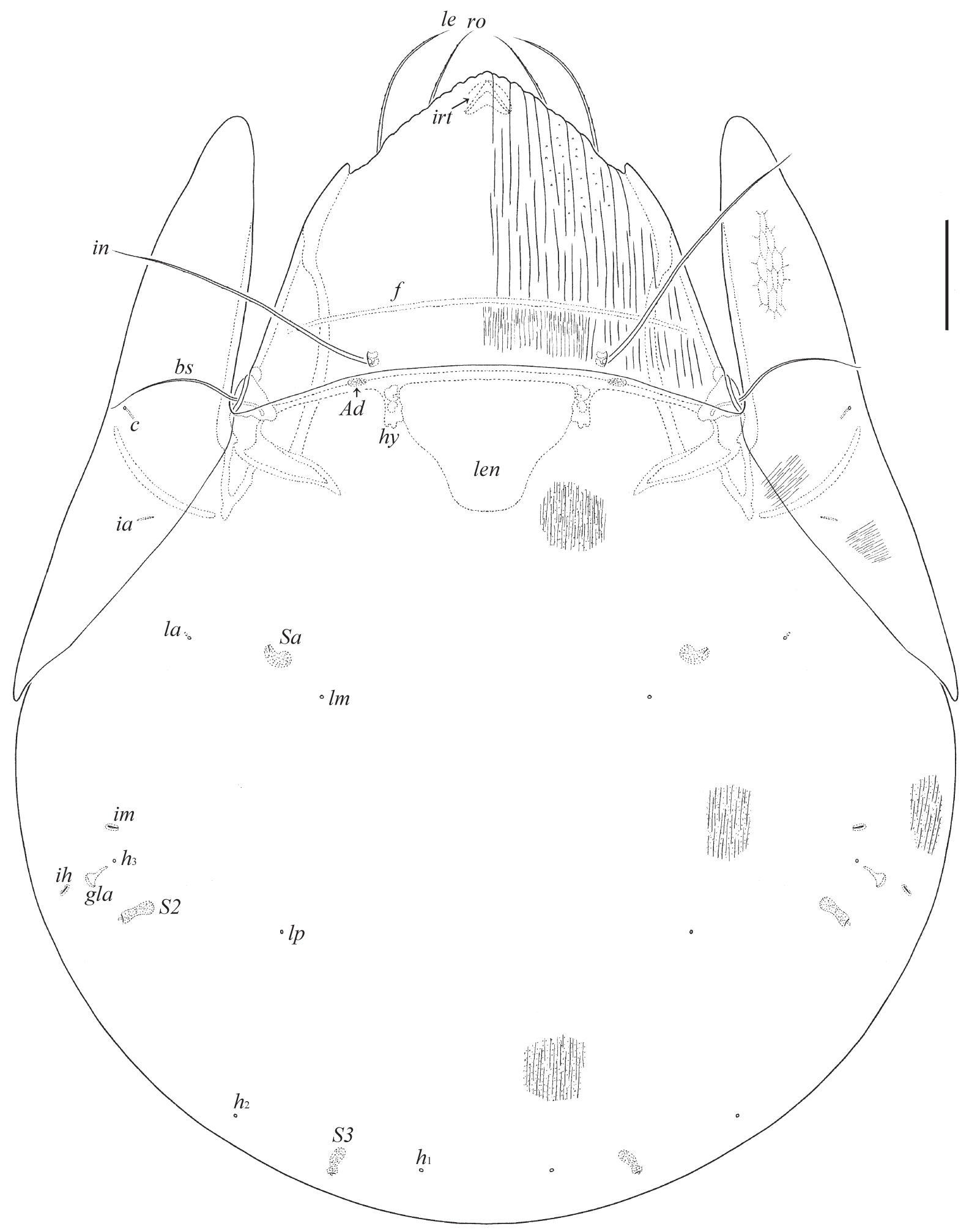

Fig. 1. Sacculogalumna hexasacculata Ermilov sp. n., adult: dorsal view. Scale bar $100 \mu \mathrm{m}$.

notogaster width: 913 (holotype), 879-996 (eight paratypes). Females larger than males: 1095-1178 $\times 929-996$ vs. $1012-1095 \times 879-962$.

Integument (Figs. 1-3, 6, 12-17). Body color dark brown to black. Body surface (including pteromorphs, subcapitular mentum, genital and anal plates) densely microgranulate (diameter of granules up to 1), anterior part of prodorsum and central part of epimere I with larger granules (up to 4). Prodorsum (except basal part between interlamellar setae) heavily striate, notogaster, pteromorphs, anogenital region, genital and anal plates, subca- 


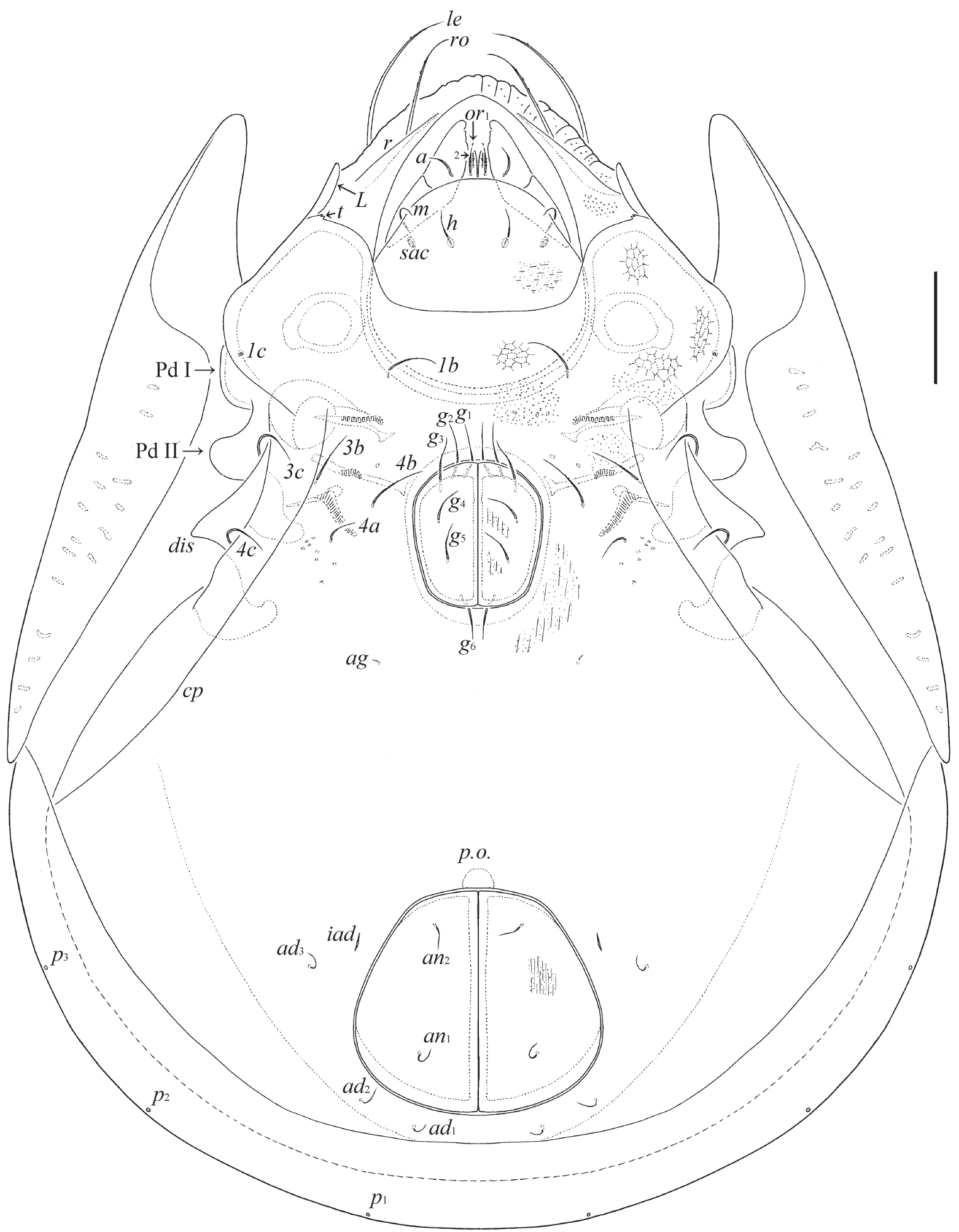

Fig. 2. Sacculogalumna hexasacculata Ermilov sp. n., adult: ventral view (legs not illustrated). Scale bar $100 \mu \mathrm{m}$.

pitular mentum and part of prodorsum between interlamellar setae finely striate. Epimere I and anterior part of pteromorphs with reticulate pattern.

Prodorsum (Figs. 1-3, 12, 13). Rostrum narrowly rounded. Lobe with projects, creating Mshaped inner excavation and inner rostral tooth (irt).
Rostrophragma ( $r p$ ) relatively thick. Basal part with slightly developed transverse furrow $(f)$. Lamellar lines $(L)$ slightly thickened, sublamellar lines $(S)$ thin, both parallel, curving backwards. Lateral structures $N$ and ridges $E$ and $T$ well-developed. Rostral (ro, 114-123) and lamellar (le, 155-164) setae seti- 
S. G. Ermilov and S. Friedrich

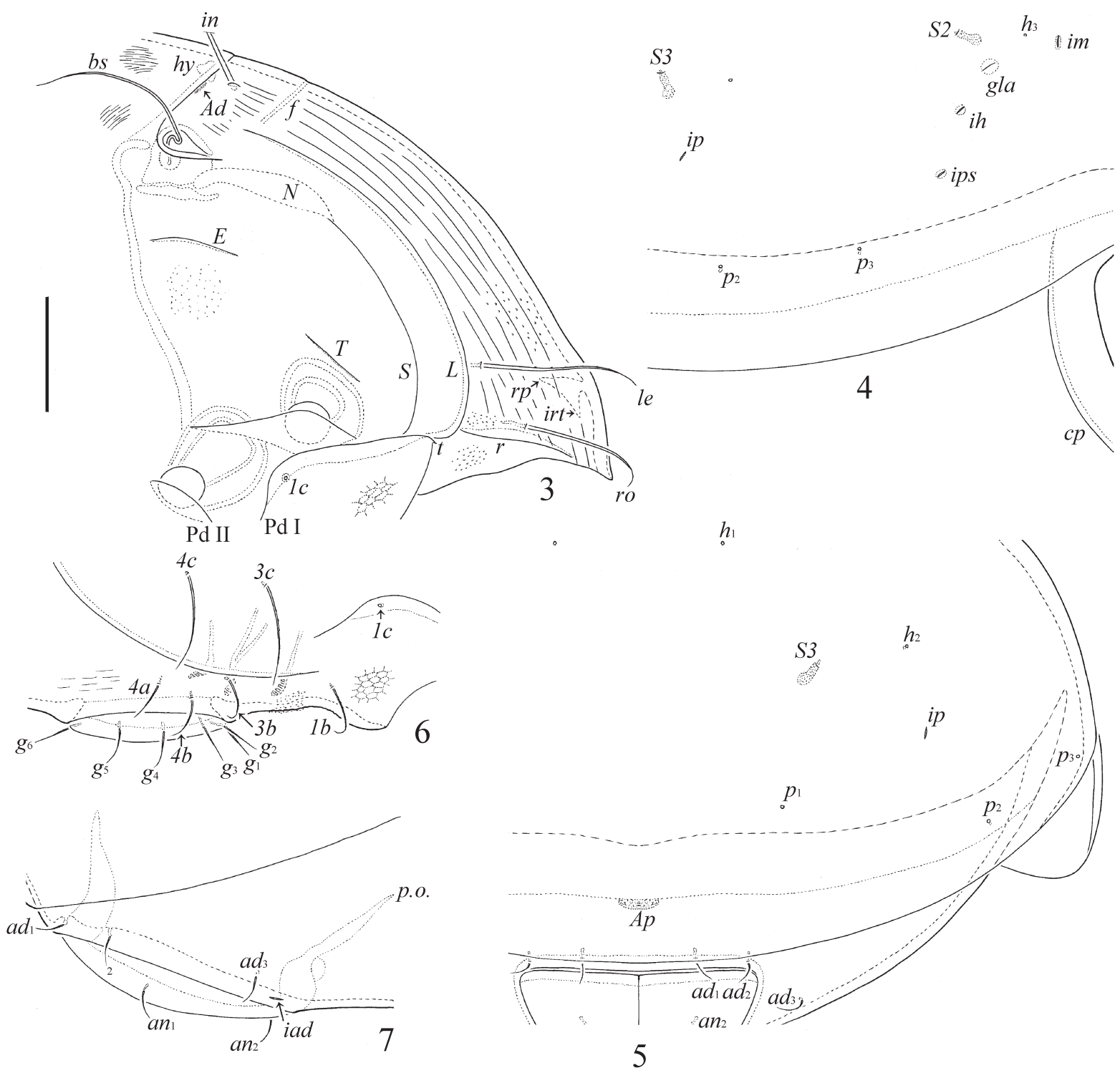

Figs. 3-7. Sacculogalumna hexasacculata Ermilov sp. n., adult: 3-anterior part of body, lateral view (pteromorph, gnathosoma and legs I, II not illustrated); 4-lateral part of body, lateral view; 5-posterior part of body, posterior view; 6-epimeral region, lateral view; 7-ano-adanal region, lateral view. Scale bar $100 \mu \mathrm{m}$.

form, barbed, le inserted between lamellar lines. Interlamellar setae (in, 287-307) setiform, with attenuate tips, sparsely barbed. Bothridial setae (bs, 168-184) setae setiform, smooth. Exobothridial setae and porose areas $A l$ absent. Sejugal porose areas $(A d, 20 \times 8)$ narrowly elongate oval, transversely oriented, posterolateral to in. Dorsophragmatic apophyses (hy) represented by group of low, roughened thickenings collectively elongated longitudinally, with variable number of components.

Notogaster (Figs. 1-5, 14, 15, 18-20). Sejugal suture complete. Triangular lenticulus (len) developed, but without distinct borders. With 10 pairs of setal alveoli and three pairs ( $S 1$ absent) of elongate sacculi ( $S a, S 2, S 3$, length 28-36), $h_{3}$ inserted anterior to $S 2$, $S a$ located between $l a$ and $l m$. Median pore absent in females and males. All lyrifissures (ia, im, ip, ih, ips) distinct, im located anterior to $h_{3}$ and $S 2$, ip posterolateral to $S 3$, ih and ips posterolateral to $S 2$. Opisthonotal gland opening ( $\mathrm{gla}$ ) anterolateral to $S 2$.

Gnathosoma (Fig. 2). Morphology of subcapitulum, palps and chelicerae typical for many species of Galumnidae (e.g. Ermilov and Anichkin 2010; Ermilov and Corpuz-Raros 2017; Ermilov and Starý 2017). Subcapitulum size: 246-254 × 205-213. Three pairs of subcapitular setae setiform, $h$ (49-57) and $m$ (45-53) barbed, little thinner than $a$ (45-53) slightly barbed. Two pairs of adoral setae $\left(o r_{1}, o r_{2}, 24\right)$ setiform, densely barbed. Length of 


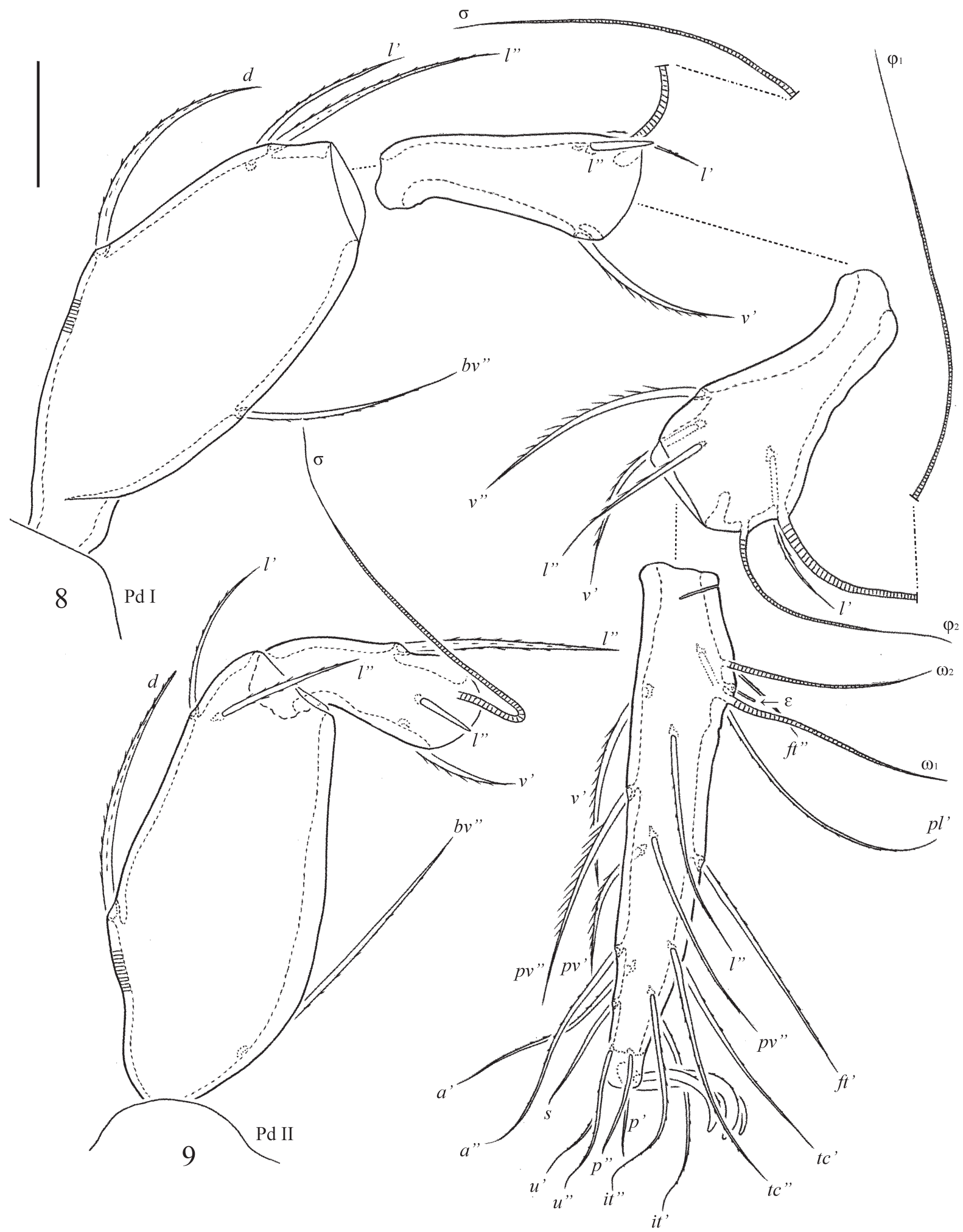

Figs. 8-9. Sacculogalumna hexasacculata Ermilov sp. n., adult: 8-leg I, without trochanter, right, antiaxial view; 9-femur and genu of leg II, right, antiaxial view. Scale bar $50 \mu \mathrm{m}$.

palps: 180-188. Axillary sacculi (sac) distinct, slightly elongated (length 12). Postpalpal setae (10) spiniform. Length of chelicerae: 316-328. Dorsoparaxial sides with several conical teeth. Two cheliceral setae setiform, barbed, cha (82-90) longer than chb (49-53). Trägårdh's organ (Tg) long, elongate triangular (length 102-106).

Epimeral and lateral podosomal regions (Figs. $2,3,6,16)$. Lateral parts of anterior tectum of epimere I with one or two small teeth $(t)$. Pedotecta I 


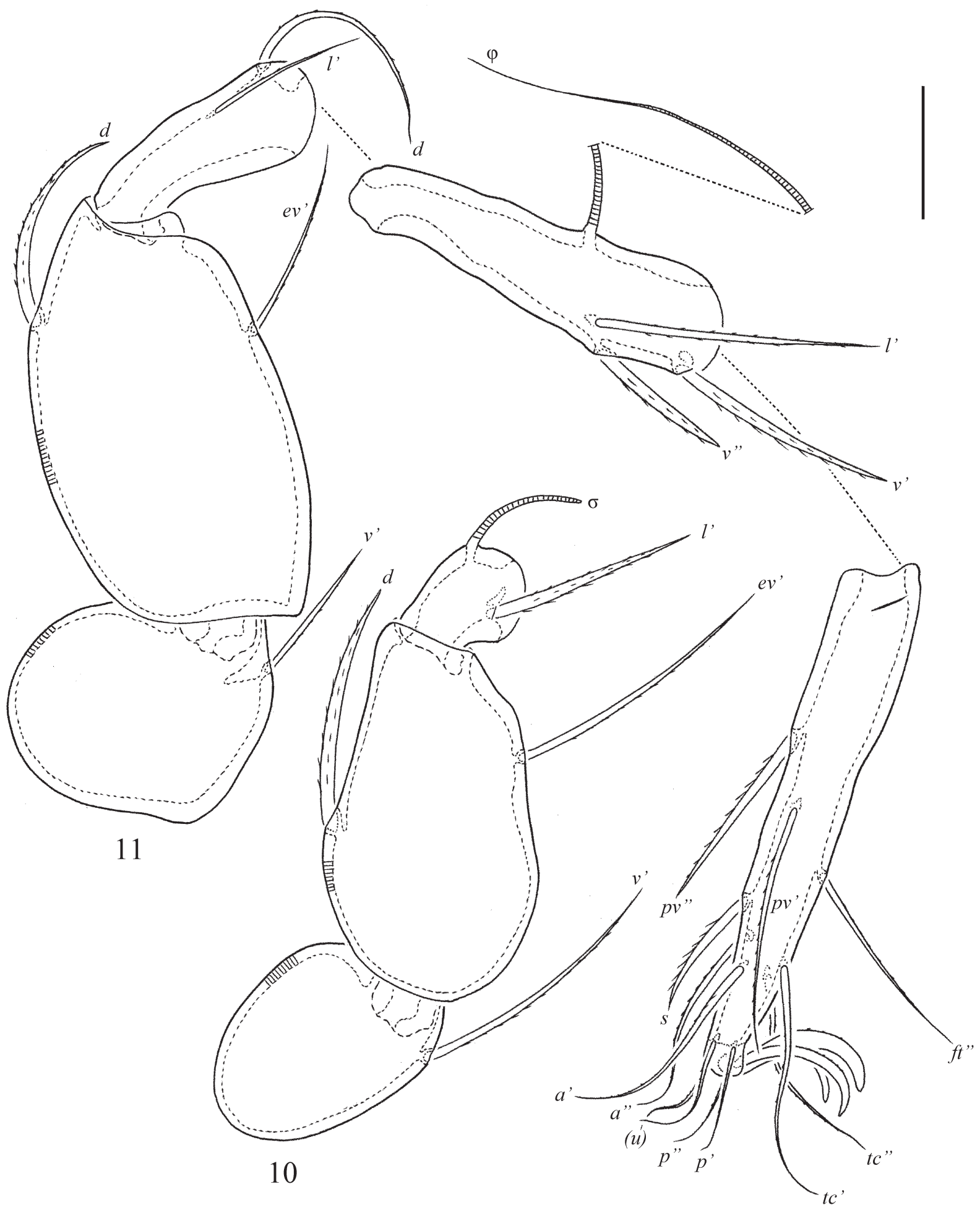

Figs. 10-11. Sacculogalumna hexasacculata Ermilov sp. n., adult: 10 - trochanter, femur and genu of leg III, left, antiaxial view; 11 - leg IV, left, antiaxial view. Scale bar $50 \mu \mathrm{m}$.

(Pd I) and II (Pd II) rounded distally in ventral view. Discidia (dis) triangular. Circumpedal carinae $(c p)$ well-developed, reaching level of apodemes II. Epimeral setal formula 2-0-2-3. Epimeral setae $1 c$ represented by alveoli, other setae setiform, slightly barbed, $3 c$ and $4 c$ longest (77-90), $4 a(41-45)$ shorter than $1 b, 3 b$, and $4 b(53-61)$.
Anogenital region (Figs. 2, 5, 7). Six pairs of genital setae $\left(g_{1}-g_{6}\right)$ of medium size $(41-45)$, setiform, slightly barbed. Anterior edges of genital plates with two setae. One pair of aggenital ( $a g$, 8-10), two pairs of anal $\left(a n_{1}, a n_{2}, 24-28\right)$ and three pairs of adanal $\left(a d_{1}-a d_{3}, 24-28\right)$ setae setiform, thin, smooth. Aggenital setae inserted located postero- 


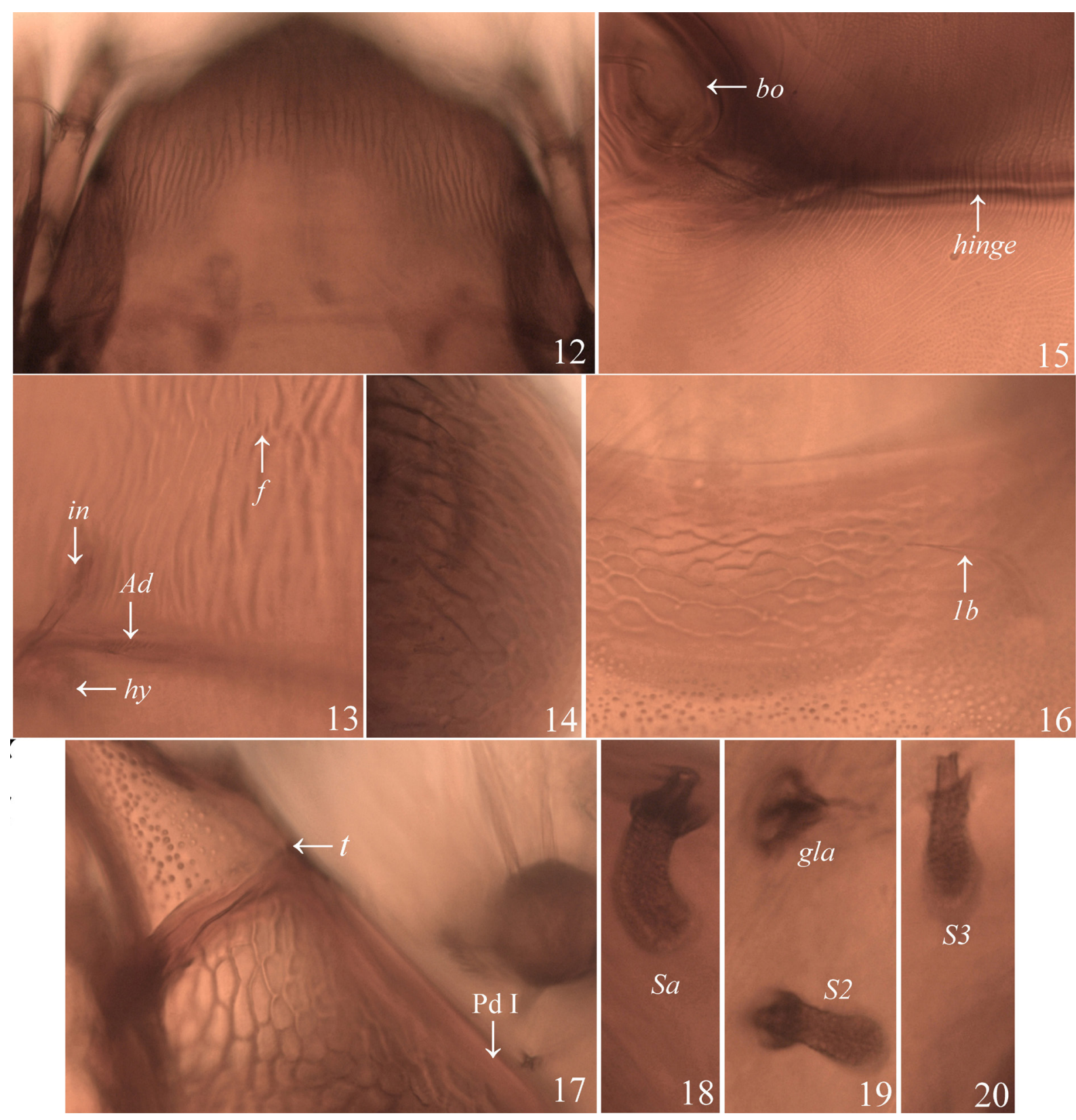

Figs. 12-20. Sacculogalumna hexasacculata Ermilov sp. n., adult, microscope images: 12 - striate ornamentation on prodorsum; 13 - striate ornamentation and transverse furrow in basal part of prodorsum; 14 - reticulate ornamentation on pteromorph; 15 - striate ornamentation on pteromorph and notogaster near to hinge; 16 - reticulate ornamentation in central part of epimere I; 17—reticulate ornamentation in lateral part of epimere I; 18 - saccule $S a$; 19 - saccule $S 2$ and opisthonotal gland; 20 - saccule $S 3$.

lateral to genital plates, distinctly closer to genital aperture than anal aperture. Adanal lyrifissures ( $\mathrm{iad}$ ) located parallel to anal plates and slightly distanced from them. Adanal setae $a d_{1}$ and $a d_{2}$ postanal, $a d_{3}$ paraanal and posterolateral to iad. Preanal organ (p.o.) elongate narrowly conical (Fig. 7). Distance $a d_{1}-a d_{2}$ distinctly shorter than $a d_{2}-a d_{3}$. Unpaired postanal porose area $(A p)$ hardly visible, elongate oval $(32-36 \times 12-16)$. Ovipositor is typical for Galumnidae (Ermilov 2010), elongated $(405 \times 86$ ), three blades (172) shorter than length of distal sec- tion (beyond middle fold; 233). Setae of blades smooth, $\psi_{1} \approx \tau_{1}$ (94) setiform, longer than thorn-like $\psi_{2} \approx \tau_{\mathrm{a}} \approx \tau_{\mathrm{b}} \approx \tau_{\mathrm{c}}(45-49)$ and coronal setae $(k, 16)$.

Legs (Figs. 8-11). Median claw distinctly thicker than laterals, all barbed on dorsal sides. Porose areas on all femora and on trochanters III, IV slightly visible. Formulas of leg setation and solenidia: I (1-4-3-4-20) [1-2-2], II (1-4-3-415) [1-1-2], III (1-2-1-3-15) [1-1-0], IV (1-2$2-3-12)[0-1-0]$; homologies of setae and solenidia indicated in Table 1. Solenidia of tibiae IV in- 
serted in anterior part of the segments. Famuli on tarsi I inserted posterior to solenidia $\omega_{1}$.

Material examined. Holotype (male) and eight paratypes (four females and four males): see "Material and Methods" section.

Type deposition. The holotype is deposited in the collection of the Museo de Historia Natural, Universidad Nacional Mayor de San Marcos, Lima, Peru; one paratype is deposited in the collection of the Bavarian State Collection of Zoology, Munich, Germany; one paratype is deposited in the collection of the Senckenberg Institute, Görlitz, Germany; six paratypes are deposited in the collection of the Tyumen State University Museum of Zoology, Tyumen, Russia.

Etymology. The specific name hexasacculata refers to the presence of six notogastral sacculi.

Differential diagnosis. Sacculogalumna hexasacculata Ermilov sp. n. is morphologically most similar to $S$. samarensis Ermilov et Corpuz-Raros, 2017 (see Ermilov and Corpuz-Raros 2017) in some general traits (rostral, lamellar and interlamellar setae well-developed; lamellar setae inserted between lamellar lines; bothridial setae setiform; three pairs of notogastral sacculi; pteromorphs with reticulate pattern). However, the new species differs from the latter by the presence of striate pattern on dorsal and ventral sides of body (vs. absent), rounded rostrum (vs. pointed), smooth bothridial setae (vs. barbed), complete sejugal suture (vs. interrupted medially), short and thin anal and adanal setae (vs. medium size, thickened), setiform genital and central epimeral setae (vs. thickened) and two setae on anterior edges of genital plates (vs. one), and the paraanal position of adanal lyrifissures in females and males (vs. inverse apoanal in females, preanal in males).

\section{ACKNOWLEDGEMENTS}

We cordially thank Dr. Juliane Diller and Erich Diller for kindly inviting Stefan Friedrich to Panguana; Franz Wachtel (Grünwald, Germany) for expertise and assistance in the field and allocation of the Winkler extractors; Dr. Gerardo Lamas Müller and Dr. Diana Silva Dávila (Museo de Historia Natural, Universidad Nacional Mayor de San Marcos, Lima, Peru) for cooperation; and the Servicio Nacional Forestal y de Fauna Silvestre (SERFOR) for issuing a collecting permit (\# 007-2014-SERFOR-DGGSPFFS) and export permit (\# 0001757-SERFOR).

This project was supported by Prof. Dr. Roland Melzer (Zoologische Staatssammlung Mün- chen, München, Germany) and the „Freunde der Zoologischen Staatssammlung“. An overarching project, study of South American mites, was supported by the Russian Science Foundation (project \# 14-14-01134).

\section{REFERENCES}

Engelbrecht, C.M. 1973. South African Galumnoidea (Oribatei: Acari): new taxa and records. Navorsinge van die Nasionale Museum, Bloemfontein, 2 (2): 394-415.

Ermilov, S.G. 2010. The structure of ovipositors in higher oribatid mites (Acari, Oribatida, Brachypylina). Zoologichesky Zhurnal, 89 (6): 694-702. [in Russian; English version: Entomological Review, 2006, 90 (6): 783-792].

Ermilov, S.G. 2016. Contribution to the knowledge of the oribatid mite genus Aeroppia (Acari, Oribatida, Oppiidae). Zootaxa, 4138 (2): 349-362.

Ermilov, S.G. and Anichkin, A.E. 2010. Three new species of Galumnidae (Acari: Oribatida) from Cat Tien National Park, southern Vietnam. Zootaxa, 2681: 20-34.

Ermilov, S.G. and Corpuz-Raros, L. 2017. First record of the genus Sacculogalumna (Acari: Oribatida: Galumnidae) from the Philippines, with description of a new species. Tropical Zoology. Accepted in Press.

Ermilov, S.G. and Friedrich, S. 2016. New species of the genera Scheloribates and Perscheloribates (Acari, Oribatida, Scheloribatidae) from Amazonian Peru. Systematic and Applied Acarology, 21 (6), 703-712.

Ermilov, S.G. and Friedrich, S. 2017. Additions to the knowledge of the oribatid mite genus Kalyptrazetes (Acari, Oribatida, Microzetidae). Systematic and Applied Acarology, 22 (3): 333-340.

Ermilov, S.G. and Gwiazdowicz, D. J. 2015. Peruvian oribatid mites (Acari: Oribatida) from the German Biological Expedition, with description of a new species of the genus Pergalumna. ZooKeys, 487: 87-96.

Ermilov, S.G. and Starý, J. 2017. Two new species of the genus Pergalumna (Acari, Oribatida, Galumnidae) from Northern Vietnam. Systematic and Applied Acarology, 22 (4): 494-508.

Ermilov, S.G., Niedbała, W. and Friedrich, S. 2016. Additions to the Peruvian oribatid mite fauna, including new records and descriptions of three new species. Spixiana, 39 (1): 61-74.

Liang, W., Yang, M. and Huang, R. 2012. First record of the genus Sacculogalumna Engelbrecht (Oribatida: Galumnidae) in China. Entomotaxonomia, 34 (2): 489-493. 
Norton, R.A. 1977. A review of F. Grandjean's system of leg chaetotaxy in the Oribatei (Acari) and its application to the family Damaeidae. In: Dindal, D.L. (Editor). Biology of oribatid mites. Syracuse: SUNY College of Environmental Science and Forestry: 33-61.

Norton, R.A. and Behan-Pelletier, V.M. 2009. Oribatida. In: Krantz, G.W. and Walter, D.E. (Editors). A Manual of Acarology (TX): Lubbock, Texas University Press. Chapter 15: 430-564.
Subías, L.S. 2004. Listado sistemático, sinonímico y biogeográfico de los ácaros oribátidos (Acariformes: Oribatida) del mundo (excepto fósiles). Graellsia, 60 (número extraordinario): 3-305. Online version accessed in February 2017, 598 pp.; http://escalera.bio.ucm.es/usuarios/bba/cont/docs/ RO_1.pdf

Travé, J. and Vachon, M. 1975. François Grandjean. 1882-1975 (Notice biographique et bibliographique). Acarologia, 17 (1): 1-19.

Table 1.

Leg setation and solenidia of adult Sacculogalumna hexasacculata Ermilov sp. n.

\begin{tabular}{|l|l|l|l|l|l|}
\hline Leg & \multicolumn{1}{|c|}{$\operatorname{Tr}$} & \multicolumn{1}{|c|}{$\mathrm{Fe}$} & \multicolumn{1}{|c|}{$\mathrm{Ge}$} & \multicolumn{1}{|c|}{ Ti } & \multicolumn{1}{|c|}{ Ta } \\
\hline I & $v^{\prime}$ & $d,(l), b v^{\prime \prime}$ & $(l), v^{\prime}, \sigma$ & $(l),(v), \varphi_{1}, \varphi_{2}$ & $(f t),(t c),(i t),(p),(u),(a), s,(p v), v^{\prime},(p l), l^{\prime \prime}, \varepsilon, \omega_{1}, \omega_{2}$ \\
\hline II & $v^{\prime}$ & $d,(l), b v^{\prime \prime}$ & $(l), v^{\prime}, \sigma$ & $(l),(v), \varphi$ & $(f t),(t c),(i t),(p),(u),(a), s,(p v), \omega_{1}, \omega_{2}$ \\
\hline III & $v^{\prime}$ & $d, e v^{\prime}$ & $l^{\prime}, \sigma$ & $l^{\prime},(v), \varphi$ & $(f t),(t c),(i t),(p),(u),(a), s,(p v)$ \\
\hline IV & $v^{\prime}$ & $d, e v^{\prime}$ & $d, l$, & $l^{\prime},(v), \varphi$ & $f t^{\prime},(t c),(p),(u),(a), s,(p v)$ \\
\hline
\end{tabular}

Note: Roman letters refer to normal setae, Greek letters refer to solenidia (except $\varepsilon=$ famulus). Single prime (') marks setae on the anterior and double prime (") setae on the posterior side of a given leg segment. Parentheses refer to a pair of setae. $\mathrm{Tr}$ - trochanter, $\mathrm{Fe}-$ femur, $\mathrm{Ge}-\mathrm{genu}, \mathrm{Ti}-\mathrm{Tibia}, \mathrm{Ta}-\operatorname{tarsus}$. 